\title{
The BCS Information Retrieval Specialist Group
}

\author{
Ingo Frommholz $\cdot$ Udo Kruschwitz $\cdot$ John Tait
}

Published online: 4 February 2014

(C) Springer-Verlag Berlin Heidelberg 2014

\section{Introduction}

The British BCS, The Chartered Institute for IT ${ }^{1}$ (also known as the British Computer Society) is a UK-based international organisation whose goal it is to bridge the gap between education, practise and research in Information Technology, providing a scope similar to the German Gesellschaft für Informatik in this respect. BCS is one of the leading professional and learned societies in the field of computers and information systems. With members in over 100 countries it consists of local UK branches and international sections as well as more than 50 Specialist Groups. One of them is the Information Retrieval Specialist Group (BCS-IRSG) as a representative for the growing field of Information Retrieval (IR). The BCS-IRSG can be regarded as the British equivalent to the German GI-Fachgruppe Information Retrieval, however with a more international focus.

In this article we are going to briefly introduce the BCSIRSG and its main activities.

${ }^{1}$ http://www.bcs.org/.

I. Frommholz (凶)

Department of Computer Science and Technology, Institute for

Research in Applicable Computing, University of Bedfordshire, Luton, UK

e-mail: ingo.frommholz@beds.ac.uk

U. Kruschwitz

School of Computer Science and Electronic Engineering,

University of Essex, Colchester, UK

e-mail: udo@essex.ac.uk

J. Tait

JohnTait.net Limited, Stockton-on-Tees, UK

e-mail: john@johntait.net

\section{Aim and History}

Established in 1978, the main aim of the IRSG is supporting the communication between IR researchers and practitioners, promoting the use of IR methods in industry and raising public awareness of IR-related topics. Recognising IR as an interdisciplinary field, a further aim of the IRSG is act as a link between computer science, library and information science and also cognate communities (like natural language processing). Another part of its mission is to provide a focus for the European IR community.

The IRSG regularly issues an online newsletter and has been co-organising some of the most prestigious events in IR. Currently the IRSG has over 500 full, voting, members (i.e. professional members of the BCS who are also members of the IRSG) and several hundred associate, nonvoting, members. The IRSG is free to join and welcomes members from all over the world. Its steering committee consists of 14 members who are academics, researchers and practitioners working in IR. ${ }^{2}$

\section{Activities}

The BCS-IRSG has been conducting, supporting and sponsoring a series of events to fulfil its mission. Among them are a newsletter (Informer), conferences and workshops as well as an annual general meeting. The IRSG also coorganises two major awards (the Karen Spärck Jones Award and the Tony Kent Strix Award).

\footnotetext{
${ }^{2}$ An interesting fun fact is that currently 3 committee members are Germans working in the UK. Therefore strong connections exist with the related German Fachgruppe Information Retrieval.
} 


\subsection{Informer}

Informer $^{3}$ has been the quarterly newsletter of the IRSG for a good 20 years. Originally distributed as a PDF file, it has now moved to an online format since its relaunch in winter 2012. The newsletter regularly contains a range of different articles including feature articles written by practitioners or academics, conference reviews, book reviews as well as an events diary.

The editorial team welcomes contributions from the international IR community and would also be happy to see guest editors taking over the organisation of an entire issue. Past examples included issues focusing on IR activities in Switzerland, Spain, respectively, and articles about the German IR landscape. Short pieces by $\mathrm{PhD}$ students describing their research area are also welcome. Anyone interested in reviewing a recently published Springer book on IR should contact the book editor for a free copy of the volume in exchange for a review to be included in Informer.

\subsection{Conferences}

BCS-IRSG has been supporting and organising several prestigious national and international conferences and workshops for many years. The aim of these events is to bring together practitioners from industry and research as well as junior and senior researchers. Some of the main events are ECIR, ICTIR, FDIA and Search Solutions.

\subsubsection{ECIR}

ECIR is the European Conference on Information Retrieval. It evolved from the BCS-IRSG Annual Colloquium on Information Retrieval to one of the main European IR conferences, getting its current name in 2003. The first colloquium was held in Leeds in 1979. Until 1998 ECIR (or the BCS IR Colloquium, respectively) was a UK-based event, it later took place in several European countries like France, Germany, Italy, Spain and recently Russia.

ECIR is meant to be a forum for young researchers with the aim to provide a supportive environment to present, discuss and debate their research with seasoned Information Retrieval experts. It facilitates a large student audience as well as established researchers by ensuring that the costs are minimised.

A number of workshops and tutorials are offered alongside ECIR, including an Industry Day for researchers and practitioners in the search business. The Industry Day is a fairly recent addition to ECIR. It started with a successful event at ECIR 2006 in London and has now been a regular feature of ECIR since 2010.

\footnotetext{
${ }^{3}$ http://irsg.bcs.org/informer/.
}

ECIR 2014 will be held in April in Amsterdam and ECIR 2015 will take place in Vienna. Originally alternating between the UK and the rest of Europe, in 2012 it was decided to drop this constraint and have an open call for bids for any European consortium interested in organising ECIR, reflecting its growing international reputation. Calls for bids are typically announced in spring and expected to be submitted in summer. Bids for ECIR 2016 will be assessed by the IRSG committee in the summer of 2014.

\subsubsection{ICTIR}

ICTIR is the International Conference on the Theory of Information Retrieval. As the name suggests the focus of this conference are theoretical aspects of IR. Hence is has been covering a broad spectrum of diverse research areas that are concerned with these mathematical/formal aspects of IR, including foundational issues, description or integration of models, retrieval applications, mathematical/formal techniques, existing and/or new theories and theoretical aspects. ICTIR grew out of a series of workshops at ACM SIGIR. Since 2007 it has been a biannual European conference, initially independently then under the auspices of the BCS-IRSG. It has been held in Hungary, the UK, Italy and Denmark. In the future ICTIR will be co-organised by BCSIRSG and SIGIR to extend its reach to a world-wide audience.

\subsubsection{FDIA}

FDIA is the Symposium on Future Directions in Information Access. It mainly addresses PhD students, researchers new to the field and post-doctoral researchers, providing an entertaining and exciting forum for sharing new research ideas. Past FDIAs were held in the UK, Italy, Germany and Spain, mostly in conjunction with the European Summer School in Information Retrieval (which is another event supported by the IRSG).

\subsubsection{Search Solutions}

BCS Search Solutions is dedicated to the latest innovations in web and enterprise search. This annual conference, taking place in the BCS venues in London, includes presentations, panels and keynote talks by influential industry leaders on novel and emerging applications in search and information retrieval. Search Solutions addresses practitioners in the search business and application-oriented IR researchers alike.

\subsubsection{Further Events}

Apart from these events the IRSG supports additional ones, among them the annual Enterprise Search Europe conference, joint meetings with other professional societies like 
ISKO $^{4}$ and from time to time other parts of the library and information community.

\subsection{Karen Spärck Jones Award}

Karen Spärck Jones was a Professor Emeritus of Computers and Information at the University of Cambridge and one of the most remarkable women in computer science. Her contributions to the fields of Information Retrieval (IR) and Natural Language Processing (NLP) were outstanding and highly influential. She was a regular speaker and attendee at early BCS-IRSG Research Colloquia, and very influential on the way the group evolved.

In order to honour Karen's achievements, the BCS and the IRSG have established an annual award to encourage and promote talented younger researchers who have endeavoured to advance our understanding of Information Retrieval and Natural Language Processing with significant experimental contributions. Award winners need to be within 10 years of the award of their PhD. The recipient of the award is invited to present a keynote lecture at the annual ECIR conference and presented with a trophy.

The Award has been generously sponsored by Microsoft Research since its inception.

Past winners of the Karen Spärck Jones Award are Mirella Lapata, Evgeniy Gabrilovich and Diane Kelly. The 2013 winner is Eugene Agichtein.

\subsection{Tony Kent Strix Award}

The IRSG is also a partner in the organisation of the annual Tony Kent Strix Award. ${ }^{5}$ The other partners in managing the

\footnotetext{
${ }^{4}$ http://www.isko.org/.

${ }^{5}$ http://www.ukeig.org.uk/awards/tony-kent-strix.
}

award are the UK eInformation Group (UKeiG), the Chemical Information and Computer Applications Group of the Royal Society of Chemistry and the International Society for Knowledge Organisation UK Chapter (ISKO UK).

The Award is given in recognition of an outstanding contribution to the field of information retrieval in its widest sense - thus, for example, including search and data mining. The first winner of the Award was Stephen Robertson and past winners include C.J. van Rijsbergen, Kalervo Järvelin, Doug Cutting, and Alan Smeaton. Bruce Croft was the 2013 Award winner.

\subsection{Annual General Meeting}

The BCS-IRSG holds an annual general meeting (AGM) in their BCS offices in Covent Garden, London. Here the steering committee provides information on past and future activities as well as on other items related to the group. The AGM is free and an opportunity to socialise with other IRSG members and meet up with colleagues. The AGM usually has been taken place in conjunction with the Search Solutions event.

\section{Conclusion}

In this article we introduced the BCS Information Retrieval Specialist Group and its activities. Readers interested in joining the BCS-IRSG, submitting an Informer article, hosting future ECIRs or just requesting further information may contact the authors of this article. Additional information about the IRSG and their events can be found at http://irsg.bcs.org/. 